\title{
The Wheat Pathogenesis Related Protein (TdPR1.2) Ensures Contrasting Behaviors to E. coli Transformant Cells under Stress Conditions
}

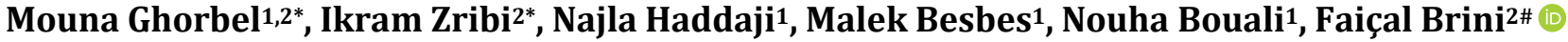 \\ ${ }^{1}$ Biology Department, Faculty of Science, University of Ha'il, Ha'il, Saudi Arabia \\ ${ }^{2}$ Biotechnology and Plant Improvement Laboratory, Centre of Biotechnology of Sfax (CBS), University of Sfax, Sfax, Tunisia \\ Email: "faical.brini@cbs.rnrt.tn
}

How to cite this paper: Ghorbel, M., Zribi, I., Haddaji, N., Besbes, M., Bouali, N. and Brini, F. (2021) The Wheat Pathogenesis Related Protein (TdPR1.2) Ensures Contrasting Behaviors to E. coli Transformant Cells under Stress Conditions. Advances in Microbiology, 11, 453-468.

https://doi.org/10.4236/aim.2021.119034

Received: August 20, 2021

Accepted: September 21, 2021

Published: September 24, 2021

Copyright $\odot 2021$ by author(s) and Scientific Research Publishing Inc. This work is licensed under the Creative Commons Attribution International License (CC BY 4.0).

http://creativecommons.org/licenses/by/4.0/

(c) (i) Open Access

\begin{abstract}
The pathogenesis-related proteins 1 (PR-1) gene family play important roles in the plant metabolism in response to biotic and abiotic stresses. The wheat TdPR1.2 has been previously isolated and characterized. Here we showed by bio-informatic analysis that TdPR1.2 contains six cysteine residues that are conserved between all PR-1 proteins tested. Using ScanProsite tool, we found that TdPR1.2 structure has a CRISP family signature 1 and 2 located at the C-terminal part of the protein. Those two domains are conserved in many identified PR1.2 proteins in plants. Moreover, SignalIP-5.0 analysis revealed that TdPR1.2 contains a putative signal peptide formed by 25 amino acids at the N-terminal extremity. The presence of this signal peptide suggested that the mature proteins will be secreted after the cleavage of the signal sequence. Further, we investigate the role of the TdPR1.2 proteins in the growth of Escherichia coli transformants cells under different abiotic stresses. Our results showed that the full-length form of TdPR1.2 enhanced tolerance of $E$. coli against salt and osmotic stress but not to $\mathrm{KCl}$. Moreover, TdPR1.2 protein confers bacterial tolerance to heavy metals in solid and liquid mediums. Based on these results, we suggest that the TdPR1.2 protein could play an important role in response to abiotic stress conditions.
\end{abstract}

\section{Keywords}

Abiotic Stress, Bioinformatic Analysis, Durum Wheat, E. coli, Growth Inhibition, Pathogen Related Proteins, Protein Expression

\footnotetext{
*These authors contributed equally to this work.
}

${ }^{*}$ Corresponding author. 


\section{Introduction}

Plants have developed complex mechanisms to protect themselves against pathogens. Pathogenesis-related (PR) genes are the key elements of these mechanisms, and are activated in response to pathogen attacks. They regulate production of several proteins, peptides or compounds which are toxic to pathogens or prevent pathogen infections where they start [1]. PR proteins have been classified under 17 different families based on their main properties [2]. Having antifungal activities, PR-1 constitutes the main family of the PR proteins induced by pathogens or salicylic acid [3]. The first member of PR-1 family, PR1-a was identified in Nicotiana tabacum plants infected with Tobacco Mosaic Virus (TMV) [4]. Subsequently, several other PR-1 proteins have been identified and characterized in monocot and dicot plant species, such as tomato (Solanum lycopersicum) [5], Triticum aestivum [6], Piper nigrum [7], Grapevine [8], Arabidopsis thaliana, Oryza sativa [9] and cassava (Manihot esculenta) [10]. Their important roles were reported in response to stress conditions [5]-[10]. The PR-1 family belongs to PR proteins (known as antimicrobial peptides, AMPs) which are classified into 17 families based on their protein sequence similarities, enzymatic activities and other biological features [2]. PR-1 proteins are considered mainly secreted and accumulated in the extracellular/apoplastic space facilitated by means of their N-terminal secretion peptide. In contrast, it was shown that some PR-1 were proteins accumulated in the vacuoles of protoplasts in tobacco [1]. Alexander et al. [11] reported that approximately $2 \%$ of the total leaf proteins in pathogen-infected tobacco plants were PR-1 proteins produced through defense response. In tomato, the expression of BG124298 (a pathogenesis-related protein-like protein gene) was 5.57 -fold upregulated in a resistant genotype while 1.63 -fold upregulated in susceptible genotype under Alternaria solani infection [12]. In another study, three distinct alkaline 14-kD proteins, $\mathrm{P} 14 \mathrm{a}, \mathrm{P} 14 \mathrm{~b}$ and $\mathrm{P} 14 \mathrm{c}$ related to the PR-1 family, showed antifungal activity against Phytophthora infestans both in vitro and in vivo conditions [13]. PR-1 genes also play important roles in response to abiotic stresses. In rice, stress-associated proteins 1 (OsSAP1) induce endogenous stress-related genes such as aminotransferase (OsAMTR1), SCP/TAPS or pathogenesis-related 1 class of protein (OsSCP) [14]. Besides, tomatoes present 13 SlPR-1 genes which were all up-regulated upon drought stress treatment [5]. Liu et al. [15] showed that a transcription regulator, Di19 (Droughtinduced) gene induced up-regulation of pathogenesis-related PR-1, PR-2 and PR-5 genes expressions in Arabidopsis. Seo et al. [16] reported that plasma membrane-tethered NAC (NAM/ATAF1/2/CUC2) transcription factor NTL6 induced some PR genes by directly binding to promoter sequences of cold-responsive PR genes, PR-1, PR-2 and PR-5. In Arabidopsis thaliana, NPR1 (the non-induced pathogenesis-related genes) control systemic acquired resistance (SAR) by regulating PR genes. NPR1 physically interacts with the TGA2 transcription factor to regulate the expression of different plant defense genes, like PR1 and PR5 [17] [18]. In a similar study, it was demonstrated that Arabidopsis PR genes were 
temporally and spatially expressed and regulated by diverse abiotic stresses and plant growth hormones such as salicylic acid (SA), jasmonic acid (JA), ethylene (ET) and brassinosteroid (BR). Interestingly, PR-3 was highly upregulated under excess salt stress in an ABA-dependent manner [16]. In wheat, TaPR-1-1 expression was induced by freezing, salinity and osmotic stresses, and the overexpression of TaPR-1-1 granted tolerance to them in yeast and Arabidopsis [19]. In tomato, pathogenesis-related protein $1 \mathrm{~b} 1$ (PR-1b1) abundance increased and remained stable till day 15 post warming in both the $556 \mathrm{HO}$ and $579 \mathrm{HO}$ transgenic tomato lines exposed to chilling temperature [20]. Over-expression of PR-1a gene in tobacco ameliorates its response to the pathogens Phytophthora parasitica var. nicotianae and Peronospora tabacina [11]. In tomato, it has been demonstrated that PR-1 strongly inhibited Phytophthora infestans's zoospores germination and the development of symptoms [13]. In pepper, CABPR1 proteins were strongly expressed after ethephon treatment, and with a lesser extent after wounding and infection by the bacterial pathogen Xanthomonas campestris pv. Vesicatoria [21]. CABPR1 proteins also ameliorate plant tolerance to heavy metal $\left(\mathrm{CdCl}_{2}\right.$ or $\left.\mathrm{HgCl}_{2}\right)$ and pathogen (Pseudomonas syringae pv. Tabaci; Phytophthora nicotianae and $R$. solanacearum) stresses [22].

Durum wheat, Triticum turgidum L. ssp durum is a tetraploid cereal $(2 n=4 x$ $=28$ chromosomes; $\mathrm{AABB}$ ), used essentially for the production of pasta and other semolina [23] that was considered as a prominent crop for 2000 years ago [24] and considered as one of the 10 most important crops all over the world [25]. Like other crops, wheat could be subjected to different abiotic and biotic stresses such as osmotic stresses which are differentially perceived by different plant organs (spike, root and shoot) [26]. For example, application of heavy metal stress $\mathrm{CuSO}_{4}$ at two different levels $(5 \mathrm{mM}$ and $25 \mathrm{mM})$ causes a reduction of fresh weight, dry matter and length. Durum wheat response to such stresses includes accumulation of soluble sugar and soluble proteins and nitrate reductase [26].

We have recently isolated and characterized a novel PR1.2 gene (TdPR1.2) from durum wheat [27]. TdPR1.2 gene was up-regulated in roots, stems and leaves after plant treatment with Salicylic Acid (SA). Besides, TdPR1.2 showed an antibacterial activity against some $\mathrm{Gram}^{+}$and $\mathrm{Gram}^{-}$bacteria and against the fungi Septoria tritici. Moreover, we provide experimental evidence that TdPR1.2 binds to calmodulins (CaMs) in Calcium dependent manner and that this binding stimulates the antimicrobial effect of TdPR1.2 in presence of both $\mathrm{Ca}^{2+}$ and $\mathrm{Mn}^{2+}$ cations [27]. In the present study, we show that TdPR1.2 protein represents a putative SCP_PR-1_like domain that belongs to SCP superfamily, conserved in other PR1 homologues. Besides, TdPR1.2 protein is much closed to monocotyledonous and dicotyledonous PR1 proteins isolated from many species indicating evolutionary conservation of PR1 genes among species. Further, we demonstrate that TdPR1.2 confers bacterial tolerance to salt and osmotic stress and not for $\mathrm{KCl}$ in E. coli transformant cells. Moreover, TdPR1.2 protein confers bacterial tolerance to heavy metals in solid and liquid mediums. As far as we know, this 
is the first report that describes the role of PR1 proteins in response to abiotic stresses in bacteria.

\section{Material and Methods}

\subsection{TdPR1.2 Protein in silico Analysis}

The 3D structure of TdPR1.2 protein was performed via the Swiss-Model server [28]. The presence of transmembrane structures was revealed by PSIPRED database (http://bioinf.cs.ucl.ac.uk/psipred). The sequence of TdPR1.2 was further studied by different database such as ScanProsite tool (https://prosite.expasy.org/). Signal sequences presence and location of their cleavage sites were predicted through SignalIP-5.0 server (http://www.cbs.dtu.dk/services/SignalP/). The subcellular localization prediction was carried out by using Plant-mPLoc server available at: http://www.csbio.sjtu.edu.cn/bioinf/plant-multi/ [29].

\subsection{TdPR1.2 Protein Expression}

In order to construct the expression vector pET28a-TdPR1.2, specific primers with restriction enzyme sites ( $E c o R I)$ were designed as follows in order to ensure an in-frame cloning sense, PR1_Ec1_Fw

(5'-GAATTCATGGCATCTTCCAAGAGT-3') and PR1_Ec1_Rev

(5'-GAATTCGGCTTCGGCGTCAAG-3'). The amplified products were cloned into the pET28a vector at the EcoRI site to express the pET28a-TdPR1.2 fusion protein, which has a poly-Histidine tag at the $\mathrm{N}$-terminus [27]. The recombinant protein His_TdPR1.2 was produced in the Rosetta E. coli strain (DE3) (Novagen) after cloning of the corresponding ORF in-frame with a poly histidine tag into the pET28a expression vectors (Novagen, Madison).

\subsection{Assays for Abiotic Stress Tolerance of E. coli Transformant Cells}

The pET28a vector and pET28a-TdPR1.2 plasmid were transformed into $E$. coli BL21 (DE3), respectively. The transformant $E$. coli cells containing either the empty vector (pET28a) or the recombinant form (pET28-TdPR1.2) were grown in Luria-Bertani (LB) liquid medium supplemented with $100 \mu \mathrm{g} / \mathrm{mL}$ kanamycine at $37^{\circ} \mathrm{C}$ for overnight. The overnight cultures were then inoculated into fresh $\mathrm{LB}$ medium (1:100 dilution) supplemented with $100 \mu \mathrm{g} / \mathrm{mL}$ kanamycine and incubated for $2-3 \mathrm{~h}$ at $37^{\circ} \mathrm{C}$ until the exponential growth phase $\left(\mathrm{OD}_{600}=0.5-0.6\right)$. Isopropylthio- $\beta$-D-galactoside (IPTG) was added to cultures to a final concentration of $1 \mathrm{mM}$, which were incubated at $37^{\circ} \mathrm{C}$ for up to $3 \mathrm{~h}$ to induce expression of the inserted gene. After induction with IPTG and incubation for $3 \mathrm{~h}$, the cells were subjected to different abiotic stress conditions $(200 \mathrm{mM} \mathrm{NaCl}, 0.5 \mathrm{M}$ $\mathrm{LiCl}, 400 \mathrm{mM}$ Sorbitol and $200 \mathrm{mM} \mathrm{KCl})$ and metallic stress conditions $(750 \mu \mathrm{M}$ $\mathrm{CuCl}_{2}, 1 \mathrm{mM} \mathrm{MnCl}_{2}, 750 \mu \mathrm{M} \mathrm{CdCl}_{2}, 750 \mu \mathrm{M} \mathrm{AlCl}_{3}, 750 \mu \mathrm{M} \mathrm{ZnSO}_{4}, 750 \mu \mathrm{M} \mathrm{Fe}-$ $\mathrm{SO}_{4}$ and $750 \mu \mathrm{M} \mathrm{CaCl}_{2}$ ). A culture without stress was also used as a control. In LB agar medium, the concentration of all induced cell cultures was diluted $10^{-1}$, 
$10^{-2}, 10^{-3} 10^{-4}, 10^{-5}$ and $10^{-6}$-fold with fresh LB medium. Then, $5 \mu \mathrm{L}$ of each dilution was spotted on mediums containing or not the appropriate stress. The results were observed then after incubation at $37^{\circ} \mathrm{C}$ for $16 \mathrm{~h}$.

For LB liquid medium, $600 \mu \mathrm{L}$ of induced cell cultures were diluted in $15 \mathrm{~mL}$ fresh LB medium and the growth pattern of control as well as stress treated cells was noted for $26 \mathrm{~h}$ by taking OD at $600 \mathrm{~nm}$ after every $2 \mathrm{~h}$ time point. The data obtained in triplicates was averaged and used to plot the graph.

\subsection{Viability Test}

$50 \mu \mathrm{L}$ of liquid assay was spaced on $\mathrm{LB}$ basal plate then incubated at $37^{\circ} \mathrm{C}$ for overnight. The result was observed by counting the number of colonies present on the medium.

\subsection{Statistical Analysis}

Each experiment was carried out in at least three replicates. Student's $t$ was performed to determine significant differences between the means of bacterial growth in unstressed and stressed mediums. The percentage presented in the following figures was calculated by the data of survival of bacteria transformed by empty pET-28a or pET-28a_TdPR1.2 grown in LB medium supplemented or not with the mentioned stress. The results were compared statistically by bacteria grown in unstressed medium and differences were considered significant at $\mathrm{p}$ $<0.01$. Mean values that were significantly different at $\mathrm{p}<0.01$ from each other are marked with asterisks $\left(^{*}\right)$.

\section{Results}

\subsection{In silico Sequence Analysis of TdPR1.2 Protein}

The full-length cDNA sequence of TdPR1.2 (GenBank accession no. MK570869.1) was structurally characterized. Sequence analysis present an ORF length of 525 bp, which encoded a protein of 174 amino acids with a predicted molecular weight of approximately $19 \mathrm{kDa}$ and an isoelectrical point (pI) of 9. In order to obtain structural insights into the TdPR1.2 protein, a 3D structural model of total protein sequence from TdPR1.2 was successfully generated using the PHYRE server [30]. The 11 best structural alignments, as provided by the server, show E-values ranging from $3 \mathrm{e}-27$ for the best hit to 0.028 for the most distant hit. The 3D model obtained with $98 \%$ coverage and has been modeled with $97.3 \%$ confidence by the single highest scoring template. The generated model illustrated the typical topology of 153 aa of TdPR1.2 protein composed of four stranded $\beta$-sheet packed against four $\alpha$-helixes (Figure 1(a)). Besides, TdPR1.2 structure was examined by Swiss model tool

(https://swissmodel.expasy.org/interactive/KZLSLh/models/01). The analysis indicated the presence of the six-cysteine motif (Figure 1(b)). Subcellular localization prediction using Plant-mPLoc server showed a vacuole localization of TdPR1.2 protein (data not shown). 
(a)

(b)
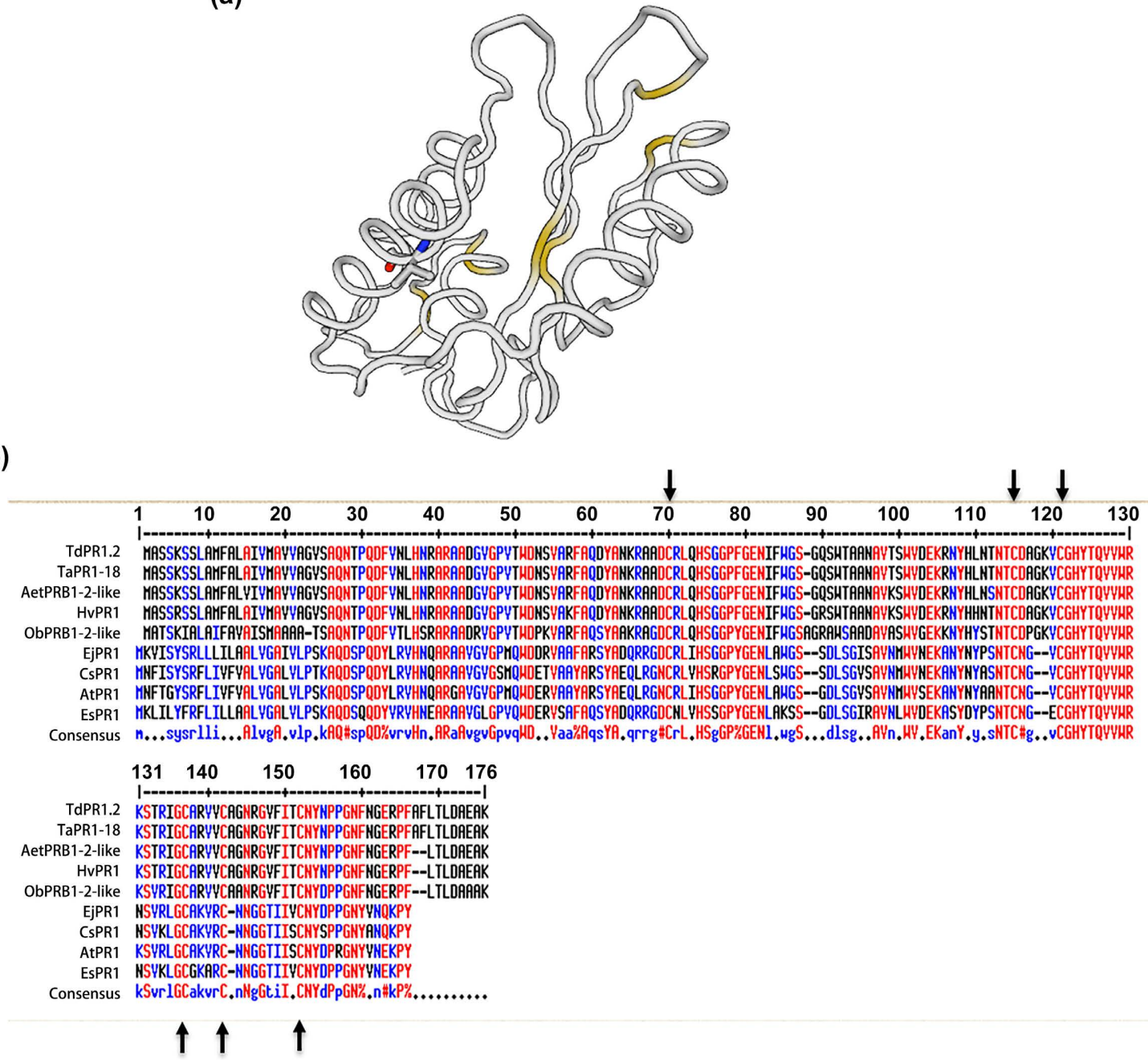

Figure 1. Bio-informatics analysis of TdPR1.2 structure. (a) 3D structure of TdPR1.2 using swiss model program (https://swissmodel.expasy.org/interactive/). (b) Sequence alignment analysis of 9 different pathogen related proteins showing the conservation of cysteine residues. Proteins used in this analysis are isolated from Triticum aestivum TdPR1-18 (AEH25633.1), PRB1.2 of Aegilops tauschii subsp. tauschii (XP_020170282.1), Hordeumvulgare (CAA88618.1), Oryza brachyantha (XP_006661674.1), Eutrema salsugineum (XP_006409652.1), Eutrema japonicum (BAF03626.1), Camelina sativa (XP_010467245.1) and Arabidopsis thaliana (NP565038.1).

To gain insights into the occurrence of signatures, the TdPR1.2 protein was analyzed by ScanProsite tool. This analysis showed that TdPR1.2, present two well conserved CRISP domains (CRISP family signature 1 and 2 (Figure 2(a)). Those domains are also conserved in some other studied proteins (Figure 2(b)). In fact, the first domain is well conserved in monocotyledonous and dicotyledonous plants investigated whereas the second domain is less conserved between monocyledonous and dicotyledonous (Figure 2(b)). Moreover, SignalIP-5.0 analysis revealed that PR1.2 contains a putative signal peptide formed by 25 amino-acids at the $\mathrm{N}$-terminal extremity (Figure 3 ). The presence of this signal peptide suggested that the mature proteins will be secreted after the cleavage of the signal sequence. Moreover, bio-informatic analysis of TdPR1.2 sequence 
(a)

ruler:

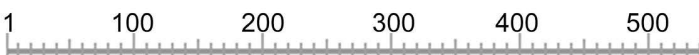

TDPR1-2

(174 aa) Individual View

PS01009 CRISP_1 CRISP family signature 1:

120 - 130: [confidence level: (0)] GHYTQVVWrkS

PS01010 CRISP_2 CRISP family signature 2:

147 - 158: [confidence level: (0)] FItCNYnPpGNF

(b)

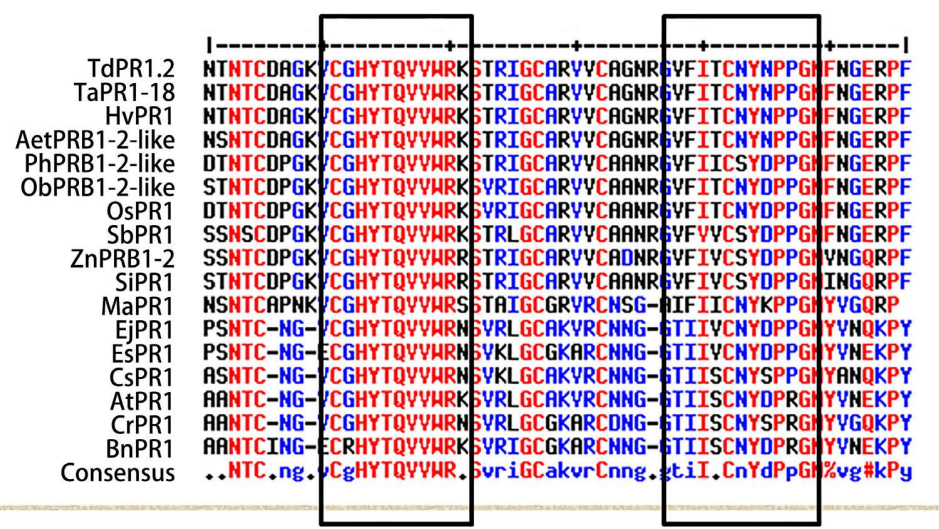

Figure 2. Identification of CRISP domain in TdPR1.2 protein. (a) TdPR1.2 contains two conserved CRISP domains in the C-terminal part of the protein as revealed by prosite database (https://prosite.expasy.org/). (b) Protein sequence alignment of different monocotyledonous and dicotyledonous proteins as revealed by multalin database.
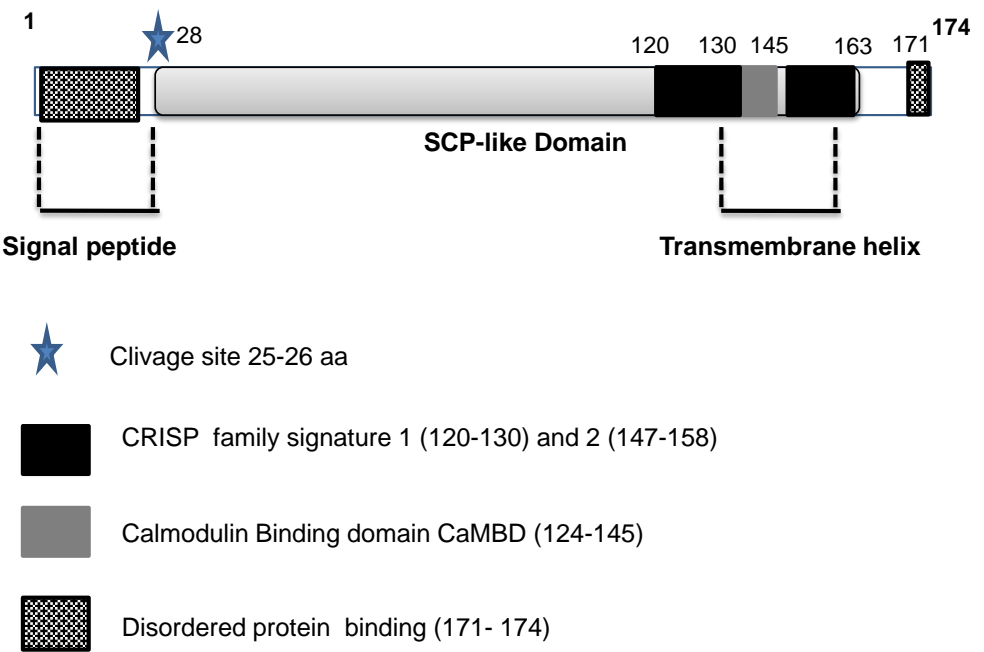

Figure 3. Schematic representation of structure and localization of the putative domains of TdPR1.2 proteins. Bioinformatic analysis reveals the presence of different conserved domains. TdPR1.2 contains a cleavage site (25 - $26 \mathrm{aa})$ and harbors a putative peptide signal region in its $\mathrm{N}$ terminal part. The peptide signal is considered as a disorder protein binding region (1 - $25 \mathrm{aa}$ ). Another peptide signal is also found in the C-terminal part of the protein $(171$ - 174). TdPR1.2 harbors also two conserved CRISP domains (120 - 130) and (147 - 158) near to the CaMBD (124 - 145). 
showed that TdPR1.2 structure does not have a Calcium binding domain as revealed by Prosite database (https://prosite.expasy.org/) (data not shown).

\subsection{Recombinants TdPR1.2 Proteins Confers Contrasting Bacterial Tolerance to Ionic and Osmotic Stress}

The biological role of TdPR1.2 in abiotic stress tolerance has been studied in vivo. For this, we used heterologous expression in $E$. coli cells. The full-length cDNA was cloned in the pET28a expression vector transformed into $E$. coli (BL21 strain) as previously described [27]. To investigate the protective properties of recombinant TdPR1.2 proteins in vivo, the growth of transformed E. coli cells with TdPR1.2 or the empty vector was determined under different stresses (LB media containing or not $0.5 \mathrm{M} \mathrm{LiCl} ; 400 \mathrm{mM}$ Sorbitol; $200 \mathrm{mM} \mathrm{NaCl}$, or 200 $\mathrm{mM} \mathrm{KCl}$ ) in solid and liquid mediums. Under standard conditions, there was no significant growth difference between all tested strains and both strains grew equivalently in solid medium (Figure $4(\mathrm{a})$ ). Whereas, under stress treatments,

(a)

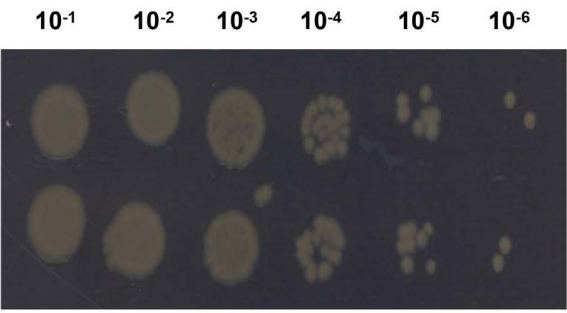

(c)
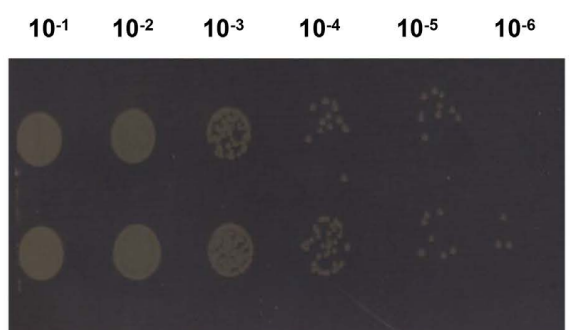

(b)

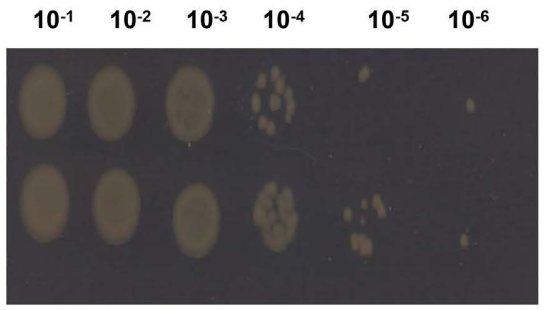

(d)

$\mathrm{NaCl} 200$ mM

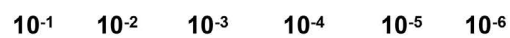

pET 28a-TdPR1

(e)

KCl 200 mM

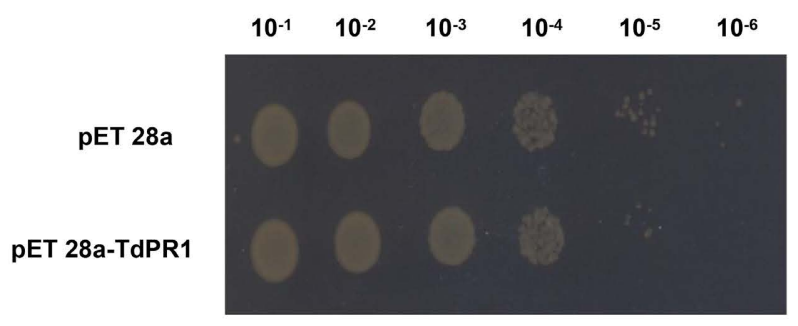

Figure 4. Functional characterization of TdPR1.2 expressed in E. coli (BL21 strain) in response to abiotic stress. Bacterial cells transformed with the empty vector (pET28a) and with the recombinant vector (pET28a + TdPR1.2) were grown for $24 \mathrm{~h}$ under normal growth conditions (a) (LB medium) or after the addition $0.5 \mathrm{M} \mathrm{LiCl} ; 400 \mathrm{mM}$ Sorbitol; $200 \mathrm{mM} \mathrm{NaCl}$, or $200 \mathrm{mM} \mathrm{KCl}$. 
cells transformed with TdPR1.2 recombinant plasmids exhibited greater growth rates in comparison with cells transformed with empty vector for all applied stresses (Figures 4(b)-(d)) except for $\mathrm{KCl}$ (Figure 4(e)). In the last case, the empty vectors transformed bacteria were more tolerant to $\mathrm{KCl}$ comparing with TdPR1.2. The same result was also observed for bacteria grown on liquid mediums. In fact, bacteria were growing equivalently in absence of stresses (Figure 5(a)) whereas in the presence of mentioned stresses, TdPR1.2 confirmed salt tolerance to $\mathrm{LiCl}$; Sorbitol; $\mathrm{NaCl}$ (Figures 5 (b)-(d)) and susceptibility to $\mathrm{KCl}$ (Figure 5(e)). The percentage of viable cells was also investigated. The number of the recombinant cells was almost the same for bacteria grown under normal conditions (Figure 6(a)), about 2.25-fold higher than control cells under $\mathrm{LiCl}$ stress (Figure 6(b)), 1.6-fold under Sorbitol stress (Figure 6(c)) and 2-fold higher under $\mathrm{NaCl}$ stress (Figure 6(d)). As expected, under $\mathrm{KCl}$ stress, bacteria transformed with empty vectors were 2 -fold higher comparing with cells transformed with pET28a (Figure 6(e)). These results indicated that the expression of TdPR1.2 in E. coli cells have different effects on their growth under different stress conditions.

\subsection{TdPR1.2 Have Dual Role in Response to Heavy Metal Stress of E. coli Cells}

The growth of $E$. coli cells containing pET28a-TdPR1.2 vectors or the empty
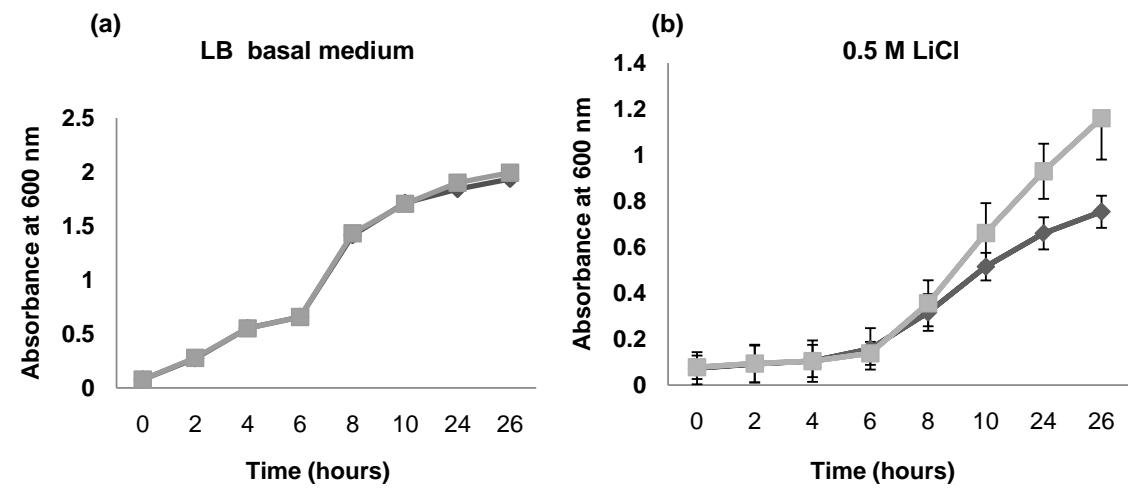

(c)
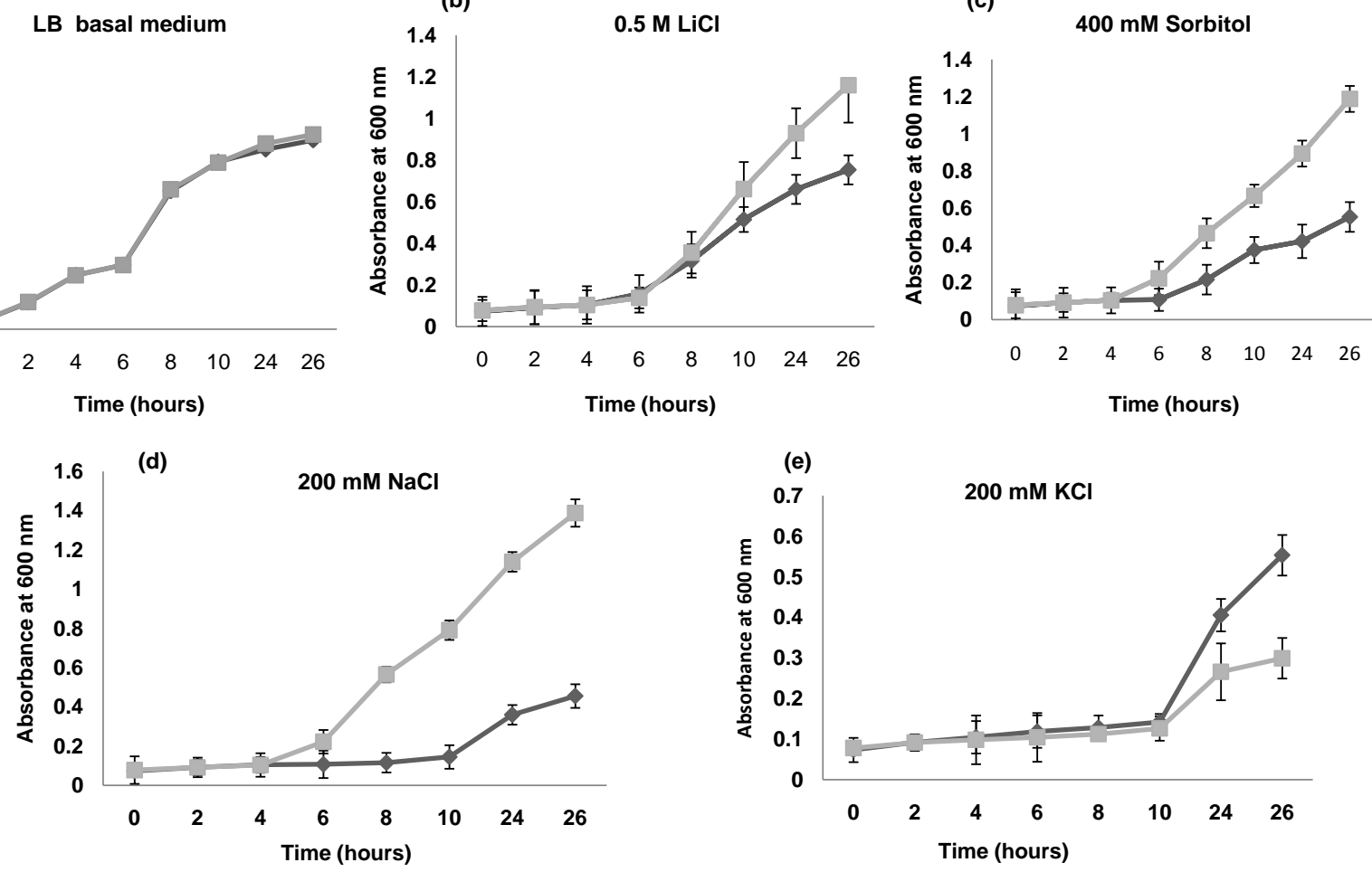

Figure 5. Behavior of TdPR1.2 transformed Bacteria in liquid LB medium in presence or absence of abiotic stress. Bacterial cells transformed with the empty vector (pET28a) and with the recombinant vector (pET28a + TdPR1.2) were grown for $24 \mathrm{~h}$ under normal growth conditions (LB medium) or after the addition $0.5 \mathrm{M} \mathrm{LiCl} ; 400 \mathrm{mM}$ Sorbitol; $200 \mathrm{mM} \mathrm{NaCl}$, or $200 \mathrm{mM} \mathrm{KCl}$. 
(a)

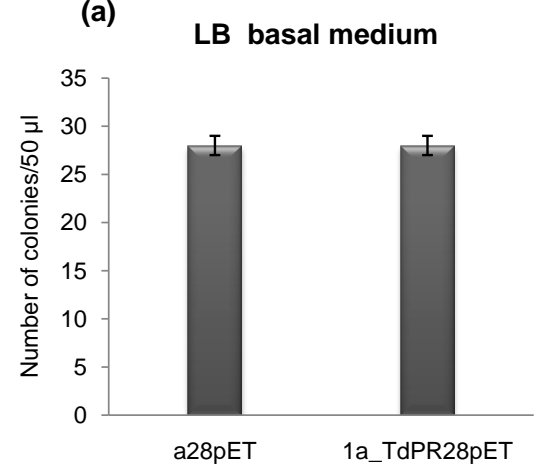

(b)

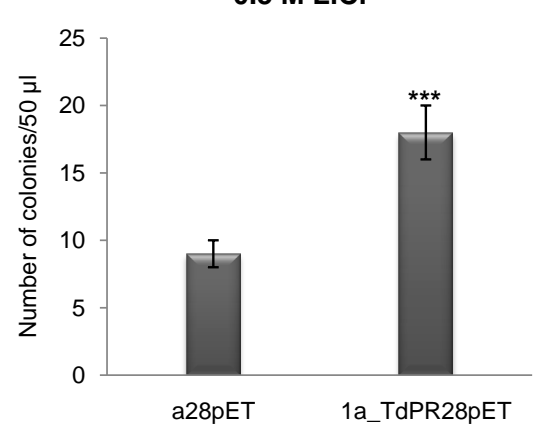

(c)

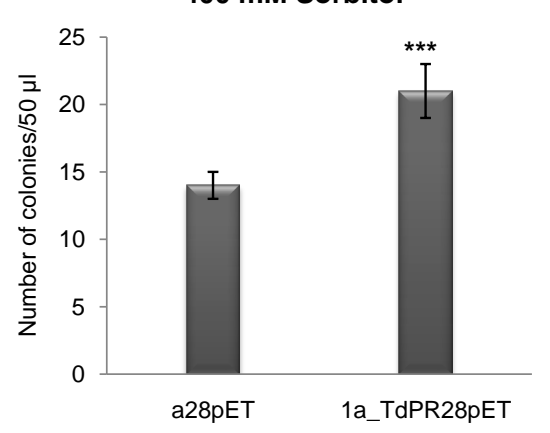

(d)

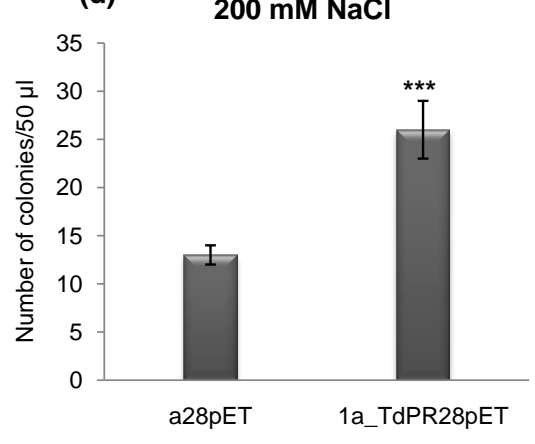

(e)

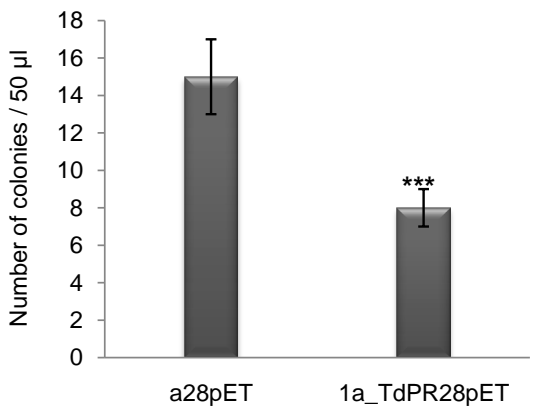

Figure 6. Presentation of percentage of cells viability under control, salt, osmotic and ionic stress conditions. Data presented are means of at least 3 independent experiments \pm S.E. Bars carrying diverse letters are significantly different $(p \leq 0.001)$ from each other, according to Duncan test results, while bars carrying the same letters are not significantly different.

vector pET28a have been analyzed in medium containing $\mathrm{AlCl}_{3}, \mathrm{CuCl}_{2}, \mathrm{CdCl}_{2}$, $\mathrm{ZnSO}_{4}, \mathrm{FeSO}_{4}, \mathrm{CaCl}_{2}$ and $\mathrm{MnCl}_{2}$ (Figure 7). In drop assays and under normal conditions, the growth pattern of recombinant cells was similar to the growth of control cells (Figure 7). However, cells transformed with pET28a-TdPR1.2 exhibited better growth in comparison with cells transformed with empty vector in the presence of all heavy metals treatments except for $\mathrm{MnCl}_{2}$ (Figure 7). These results suggested that TdPR1.2 could play a potential role in heavy metal stress tolerance.

\section{Discussion}

Abiotic stress is one of the major threats to the modern agriculture that causes not only enormous yield losses [31] [32] [33] [34], but also provides the entry points to various microbial pathogens. Subsequently, the global climate change is another threat to crop system because of increased emergence of more virulent and broad host range pathogenic strains. Therefore, studying the molecular mechanisms of plant resistance or tolerance to either biotic and abiotic stresses or multiple stresses will provide novel opportunities to develop multiple stress tolerance crops [31] [32] [33] [34] [35]. Pathogenesis-related proteins are induced by multiple stresses and seem to be important candidates for generating multiple stress tolerant crop varieties [31]-[37]. Abiotic stress mediated expression of PR 

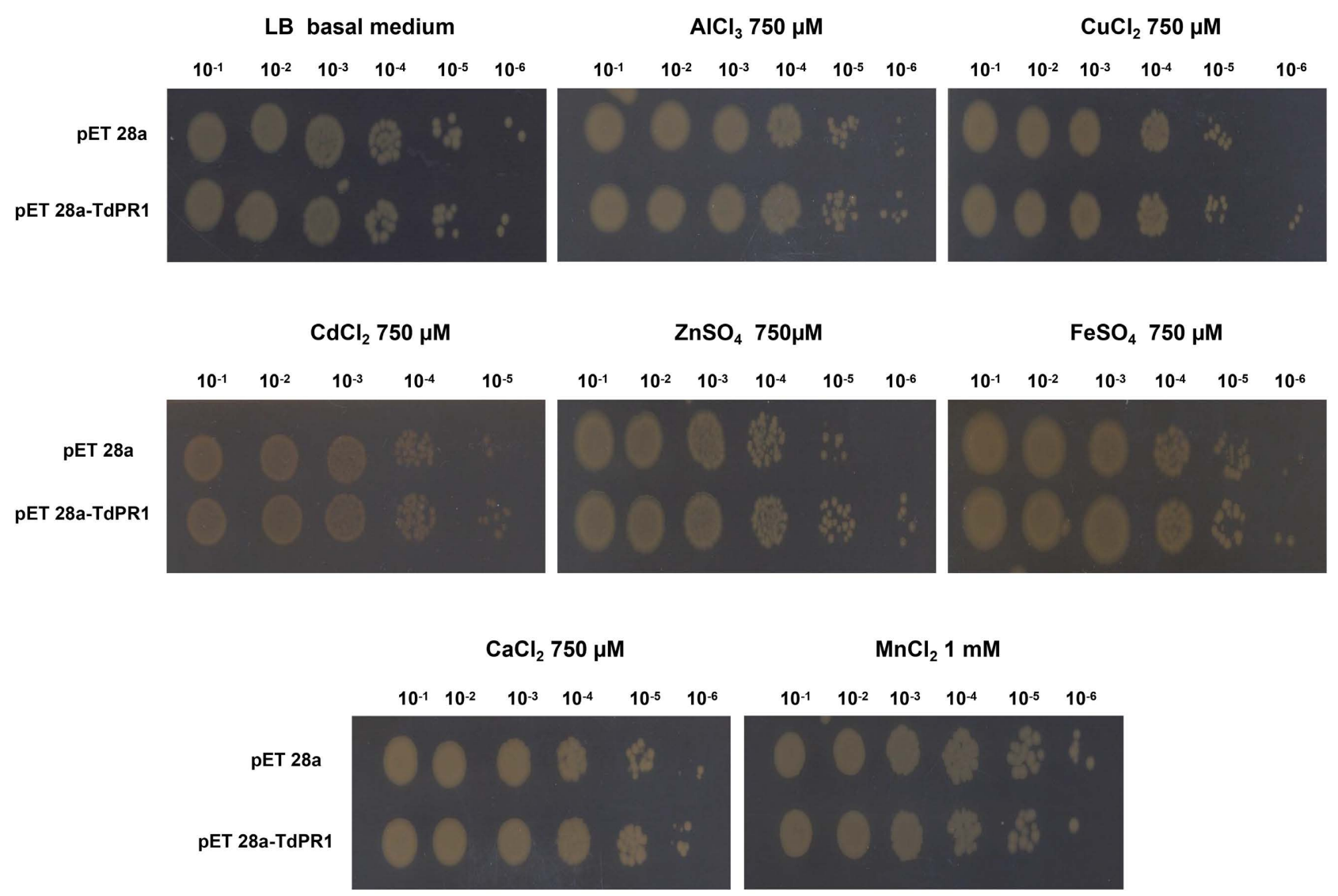

Figure 7. Functional characterization of TdPR1.2 expressed in E. coli (BL21 strain) in response to heavy metals stress. Bacterial cells transformed with the empty vector (pET28a) and with the recombinant vector (pET28a + TdPR1.2) were grown for $24 \mathrm{~h}$ under normal growth conditions (LB medium) or after the addition of $750 \mu \mathrm{M} \mathrm{AlCl}_{3}, \mathrm{CuCl}_{2}, \mathrm{CdCl}_{2}, \mathrm{ZnSO}_{4}, \mathrm{FeSO}_{4}, \mathrm{CaCl}_{2}$ and $\mathrm{MnCl}_{2}$. 
particularly well-conserved region in the two groups of proteins, suggestive of an important functional role of this domain. Mostly, two of the conserved PR-1 Cys residues involved in the formation of the disulphide bridges are absent from the vertebrate proteins. On the other hand, CRISPs contain a conserved spacing of up to 16 Cys residues in the C-terminal half, which most probably forms a discrete, compact domain [33]. It has been speculated that CRISPs might encode lytic enzymatic activities, which would be consistent with the potential role of PR1.2. These observations that PR-1 proteins form a specific family within the plant kingdom and show homologies and structural motifs in common with proteins from fungi, invertebrate and vertebrate animals and humans, make the PR-1 family a distinct and highly conserved group of proteins. Their widespread occurrence suggests that these proteins share an evolutionary origin and possess activity essential to the functioning of living organisms.

To gain insight into the role of TdPR1.2 in response to various abiotic stresses, we overexpressed it in $E$. coli cells exposed to different stresses. Our results have showed that TdPR1.2 positively regulate bacterial response to salt, sorbitol and $\mathrm{LiCl}$ except $\mathrm{KCl}$ stress. Taken together, we suggested that TdPR1.2 is functional and plays a crucial role in $E$. coli response to these abiotic stresses. In parallel, TdPR1.2 has a positive role in improving tolerance of $E$. coli cells grown in different heavy metals mediums $\left(\mathrm{AlCl}_{3}, \mathrm{CuCl}_{2}, \mathrm{CdCl}_{2}, \mathrm{ZnSO}_{4}, \mathrm{FeSO}_{4}\right.$ and $\left.\mathrm{CaCl}_{2}\right)$ but not to $\mathrm{MnCl}_{2}$. A PR-1 protein isolated from pepper, called CABPR1 was shown to have a positive role in improving tobacco plant tolerance to heavy metal stresses $\left(\mathrm{CdCl}_{2}\right.$ or $\left.\mathrm{HgCl}_{2}\right)$ [24]. Interestingly, the durum wheat TdPR1.2 protein ameliorates the growth of $E$. coli cells grown under heavy metal stresses $(\mathrm{Cd}, \mathrm{Cu}$, $\mathrm{Ca}, \mathrm{Fe}, \mathrm{Al}$ and $\mathrm{Zn})$ and ionic/osmotic stresses $(\mathrm{NaCl}, \mathrm{LiCl}$, Sorbitol). Wang et al. [21] demonstrated that TaPR-1-1 expression was also induced by freezing, salinity, and osmotic stresses. Overexpression in yeast and Arabidopsis showed that TaPR-1-1 conferred tolerance to these stresses. Hence at least some PR-1 proteins have function in biotic and/or abiotic stress tolerance. Although expression profiles of some PR-1 members were tested under pathogen attack, expression profiles of PR-1 members under abiotic stress are still not adequately studied. Some evidence indicates that PR proteins, such as PR-2 (glucanase), PR-3 (chitinase) and PR-5 (thaumatin-like protein), inhibit microbial growth through enzymatic activity [36] [37]. PR-1 proteins that contain a CAP-derived (cysteine-rich secretory protein, antigen 5 , and pathogenesis-related-1) peptide 1 have been shown to confer stress tolerance [38]. However, the actual mechanism of PR-1 in abiotic stress tolerance and whether PR-1 takes part in tolerance to both abiotic and biotic stress through the same pathway remains to be addressed.

\section{Conclusion and Future Prospects}

Although it was suggested that all proteins of the PR protein superfamily could, on the basis of present knowledge of the molecular structure, have similar functions, the most convincing homology is observed with the proteins from yeast, 
which have been implicated in morphogenesis. It must be concluded that the high extent of sequence conservation of the plant PR-1 proteins from different plant families is remarkable, but so far does not offer any clues concerning their mode of action. We characterized a novel wheat PR1 gene, TdPR1.2 in vitro after expression in E. coli transformant cells. To the best of our knowledge, this is the first report of a PR1 gene from wheat to describe its functional accreditation in imparting defense against abiotic stress in vitro. Further characterization of TdPR1.2 and its regulation under ambient and stress environments in planta will enhance our understanding of the molecular cross-talk among various signaling pathways mediating plant defense responses.

\section{Acknowledgements}

This research has been founded by Scientific Research Deanship at the University of Ha'il, Saudi Arabia through project number RG-20203.

\section{Conflicts of Interest}

The authors declare that they have no conflicts of interest.

\section{References}

[1] Breen, S., Williams, S.J., Outram, M., Kobe, B. and Solomon, P.S. (2017) Emerging Insights into the Functions of Pathogenesis Related Protein 1. Trends in Plant Science, 22, 871-879. https://doi.org/10.1016/j.tplants.2017.06.013

[2] Sels, J., Mathys, J., DeConinck, B.M., Cammue, B.P. and De Bolle, M.F. (2008) Plant Pathogenesis-Related (PR) Proteins: A Focus on PR Peptides. Plant Physiology and Biochemistry, 46, 941-950. https://doi.org/10.1016/j.plaphy.2008.06.011

[3] Van Loon, L.C. (1999) Occurrence and Properties of Plant Pathogenesis-Related Proteins. In: Datta, S.K., Ed., Pathogenesis-Related Proteins in Plants, CRC Press, Boca Raton, 1-19.

[4] Van Loon, L.C. and Van Kammen, A. (1970) Polyacrylamide Disc Electrophoresis of the Soluble Leaf Proteins from Nicotiana tabacum var. 'Samsun' and 'Samsun NN': II. Changes in Protein Constitution after Infection with Tobacco Mosaic Virus. Virology, 40, 199-211. https://doi.org/10.1016/0042-6822(70)90395-8

[5] Akbudaka, M.A., Yildiza, S. and Filiz, E. (2020) Pathogenesis Related Protein-1 (PR-1) Genes in Tomato (Solanum lycopersicum L.): Bioinformatics Analyses and Expression Profiles in Response to Drought Stress. Genomics, 112, 4089-4099. https://doi.org/10.1016/j.ygeno.2020.07.004

[6] Esmail, S.M., Aboulila, A.A. and Abd El-Moneim, D. (2020) Variation in Several Pathogenesis-Related (PR) Protein Genes in Wheat (Triticum aestivum) Involved in Defense against Puccinia striiformis f. sp. Tritici. Physiological and Molecular Plant Pathology, 112, Article ID: 101545. https://doi.org/10.1016/j.pmpp.2020.101545

[7] Kattupalli, D., Srinivasan, A. and Soniya, E.V. (2021) Genome-Wide Analysis of Pathogenesis-Related Protein-1 (PR-1) Genes from Piper nigrum Reveals Its Critical Role during Phytophthora capsici Infection. Genes, 12, Article No. 1007. https://doi.org/10.3390/genes12071007

[8] Gkizi, D., Poulaki, E.G. and Tjamos, S.E. (2021) Towards Biological Control of Aspergillus carbonarius and Botrytis cinerea in Grapevine Berries and Transcriptomic 
Changes of Genes Encoding Pathogenesis-Related (PR) Proteins. Plants, 10, Article No. 970. https://doi.org/10.3390/plants10050970

[9] Kaur, A., Pati, PK., Pati, A.M. and Nagpal, A.K. (2020) Physico-Chemical Characterization and Topological Analysis of Pathogenesis-Related Proteins from Arabidopsis thaliana and Oryza sativa Using in-Silico Approaches. PLoS ONE, 15, e0239836. https://doi.org/10.1371/journal.pone.0239836

[10] Irigoyen, M.L, Garceau, D.C., Bohorquez-Chaux, A., Lopez-Lavalle, L.A.B., Perez-Fons, L., Fraser, P.D. and Walling, L.L. (2020) Genome-Wide Analyses of Cassava Pathogenesis-Related $(P R)$ Gene Families Reveal Core Transcriptome Responses to White Fly Infestation, Salicylic Acid and Jasmonic Acid. BMC Genomics, 21, Article No. 93. https://doi.org/10.1186/s12864-019-6443-1

[11] Alexander, A., Goodman, R.M. and Gut-Rella, M. (1993) Increased Tolerance to Two Oomycete Pathogens in Transgenic Tobacco Expressing Pathogenesis-Related Protein 1a. Proceedings of the National Academy of Sciences of the United States of America, 90, 7327-7331. https://doi.org/10.1073/pnas.90.15.7327

[12] Upadhyay, P., Rai, A., Kumar, R., Singh, M. and Sinha, B. (2014) Differential Expression of Pathogenesis Related Protein Genes in Tomato during Inoculation with A. Solani. Journal of Plant Pathology and Microbiology, 5, Article No. 217.

[13] Niderman, T., Genetet, I., Bruyère, T., Gees, R., Stintzi, R., Legrand, M., Fritig, B. and Mösinger, E. (1995) Pathogenesis-Related PR-1 Proteins Are Antifungal. Isolation and Characterization of Three 14-Kilodalton Proteins of Tomato and of a Basic PR-1 of Tobacco with Inhibitory Activity against Phytophthora infestans. Plant Physiology, 108, 17-27. https://doi.org/10.1104/pp.108.1.17

[14] Kothari, K.S., Dansana, P., Jiri, J. and Tyagi, A.K. (2016). Rice Stress Associated Protein 1 (OsSAP1) Interacts with Aminotransferase (OsAMTR1) and Pathogenesis-Related 1a Protein (OsSCP) and Regulates Abiotic Stress Responses. Frontiers in Plant Science, 7, Article No. 1057. https://doi.org/10.3389/fpls.2016.01057

[15] Liu, W.X., Zhang, F.C., Zhang, W.Z., Song, L.F., Wu, W.H. and Chen, Y.F. (2013) Arabidopsis Di19 Functions as a Transcription Factor and Modulates PR1, PR2, and PR5 Expression in Response to Drought Stress. Molecular Plant, 6, 1487-1502. https://doi.org/10.1093/mp/sst031

[16] Seo, P.J., Kim, M.J., Park, J.Y., Jeon, J., Lee, Y.H., Kim, J. and Park, C.M (2010) Cold Activation of a Plasma Membrane-Tethered NAC Transcription Factor Induces a Pathogen Resistance Response in Arabidopsis. Plant Journal, 61, 661-671. https://doi.org/10.1111/j.1365-313X.2009.04091.x

[17] Boyle, P., Le Su, E., Rochon, A., Shearer, H.L., Murmu, J., Chu, J.Y., Fobert, P.R. et al. (2009) The BTB/POZ Domain of the Arabidopsis Disease Resistance Protein NPR1 Interacts with the Repression Domain of TGA2 to Negate Its Function. Plant Cell, 21, 3700-3713. https://doi.org/10.1105/tpc.109.069971

[18] Matthews, B.F., Beard, H., Brewer, E., Kabir, S., MacDonald, M.H. and Youssef, R.M. (2014) Arabidopsis Genes, AtNPR1, AtTGA2 and AtPR-5, Confer Partial Resistance to Soybean Cyst Nematode (Heterodera glycines) When Overexpressed in Transgenic Soybean Roots. BMC Plant Biology, 14, Article No. 96. https://doi.org/10.1186/1471-2229-14-96

[19] Wang, J., Mei, J. and Ren, G. (2019) Plant MicroRNAs: Biogenesis, Homeostasis, and Degradation. Frontiers in Plant Science, 10, Article No. 360.

https://doi.org/10.3389/fpls.2019.00360

[20] Goyal, R.K., Fatima, T., Topuz, M., Bernadec, A., Sicher, R., Handa, A.K. and Mattoo, A.K. (2016) Pathogenesis-Related Protein 1b1 (PR1b1) Is a Major Tomato Fruit 
Protein Responsive to Chilling Temperature and Upregulated in High Polyamine Transgenic Genotypes. Frontiers in Plant Science, 7, Article No. 901. https://doi.org/10.3389/fpls.2016.00901

[21] Kim, Y.J. and Hwang, B.K. (2000) Pepper Gene Encoding a Basic Pathogenesis-Related 1 Protein Is Pathogen and Ethylene Inducible. Physiologiae Plantarum, 108, 51-60. https://doi.org/10.1034/j.1399-3054.2000.108001051.x

[22] Sarowar, S., Kim, Y.J., Kim, E.N., Kim, K.D., Hwang, B.K., Islam, R. and Shin, J.S. (2005) Overexpression of a Pepper Basic Pathogenesis-Related Protein 1 Gene in Tobacco Plants Enhances Resistance to Heavy Metal and Pathogen Stresses. Plant Cell Report, 24, 216-224. https://doi.org/10.1007/s00299-005-0928-x

[23] Dubcovsky, J. and Dvorak, J. (2007) Genome Plasticity a Key Factor in the Success of Polyploid Wheat under Domestication. Science, 316, 1862-1866.

https://doi.org/10.1126/science.1143986

[24] Faris, J. (2014) Wheat Domestication: Key to Agricultural Revolutions Pasts and Future. In: Tuberosa, R., Graner, A. and Frison, E., Eds., Genomics of Plant Genetic Resources, Springer, Dordrecht, 439-464.

https://doi.org/10.1007/978-94-007-7572-5_18

[25] Kabbaj, H., Sall, A.T., Al-Abdallat, A., Geleta, M., Amri, A., Filali-Maltouf, A., Belkadi, B., Ortiz, R. and Bassi, F.M. (2017) Genetic Diversity within a Global Panel of Durum Wheat (Triticum durum) Landraces and Modern Germplasm Reveals the History of Alleles Exchange. Frontiers in Plant Science, 8, Article No. 1277. https://doi.org/10.3389/fpls.2017.01277

[26] Abd El-Samad, H.M., Mostafa, D. and Abd El-Hakeem, K.N. (2017) The Combined Action Strategy of Two Stresses, Salinity and $\mathrm{Cu}^{++}$on Growth, Metabolites and Protein Pattern of Wheat Plant. American Journal of Plant Sciences, 8, 625-643. https://doi.org/10.4236/ajps.2017.83043

[27] Ghorbel, M., Zribi, I., Missaoui, Kh., Drira-Fakhfekh, M., Azzouzi, B. and Brini, F. (2021) Differential Regulation of the Durum Wheat Pathogenesis-Related Protein (PR1) by Calmodulin TdCaM1.3 Protein. Molecular Biology Reports, 48, 347-362. https://doi.org/10.1007/s11033-020-06053-7

[28] Waterhouse, A., Bertoni, M., Bienert, S., Studer, G., Tauriello, G., Gumienny, R., et al. (2018) SWISS-MODEL: Homology Modelling of Protein Structures and Complexes. Nucleic Acids Research, 46, W296-W303.

https://doi.org/10.1093/nar/gky427

[29] Chou, K.C. and Shen, H.B. (2010) Plant-mPLoc: A Top-Down Strategy to Augment the Power for Predicting Plant Protein Subcellular Localization. PLoS ONE, 5, e11335. https://doi.org/10.1371/journal.pone.0011335

[30] Bairoch, A., Apweiler, R., Wu, C.H., Barker, W.C., Boeckmann, B., Ferro, S., et al. (2005) The Universal protein Resource (UniProt). Nucleic Acids Research, 33, D154-D159. https://doi.org/10.1093/nar/gki070

[31] Verma, S., Nizam, S. and Verma, P.K. (2013) Biotic and Abiotic Stress Signaling in Plants. In: Sarwat, M., Ahmad, A. and Abdin, M., Eds., Stress Signaling in Plants. Genomics and Proteomics Perspective, Vol. 1, Springer Science, New York, 25-49. https://doi.org/10.1007/978-1-4614-6372-6_2

[32] Gull, A., Lone, A.A. and Wani, N-I (2019) Biotic and Abiotic Stresses in Plants. IntechOpen, London. https://doi.org/10.5772/intechopen.85832

[33] Ali, S., Rizwan, M., Qayyum, M.F., Ok, Y.S., Ibrahim, M., Riaz, M., Arif, M.S., Hafeez, F., Al-Wabel, M.I. and Shahzad, A.N. (2017) Biochar Soil Amendment on Alleviation of Drought and Salt Stress in Plants: A Critical Review. Environmental 
Science Pollution Research, 24, 12700-12712.

https://doi.org/10.1007/s11356-017-8904-x

[34] Ghorbel, M., Saibi, W. and Brini, F. (2020) Abiotic Stress Signaling in Brassicaceae Plants. Journal of Soil and Plant Biology, No. 1, 138-150.

https://doi.org/10.33513/JSPB/2001-17

[35] Ali, S., Mir, Z.A., Bhat, J.A., Chandrashekar, N., Papolu, P.K., Rawat, S. and Grover, A. (2017) Identification and Comparative Analysis of Brassica juncus Pathogenesis-Related Genes in Response to Hormonal, Biotic and Abiotic Stresses. Acta Physiologiae Plantarum, 39, Article No. 268. https://doi.org/10.1007/s11738-017-2565-8

[36] Kiba, A., Nishihara, M., Nakatsuka, T. and Yamamura, S. (2007) Pathogenesis-Related Protein 1 Homologue Is an Antifungal Protein in Wasabia japonica Leaves and Confers Resistance to Botrytis cinerea in Transgenic Tobacco. Plant Biotechnology, 24, 247-253. https://doi.org/10.5511/plantbiotechnology.24.247

[37] van Loon, L.C., Rep, M. and Pieterse, C.M.J. (2006) Significance of Inducible Defense-Related Proteins in Infected Plants. Annual Review of Phytopathology, 44, 135-162. https://doi.org/10.1146/annurev.phyto.44.070505.143425

[38] Chien, P.S., Nam, H.G. and Chen, Y.R.A (2015) Salt-Regulated Peptide Derived from the CAP Superfamily Protein Negatively Regulates Salt Stress Tolerance in Arabidopsis. Journal of Experimental Botany, 66, 5301-5313.

https://doi.org/10.1093/jxb/erv263 